\title{
ОПЫТ ОКОНТУРИВАНИЯ ПОГРЕБЕННЫХ ДОЛИН ЭСТОНИИ ГЕОФИЗИЧЕСКИМИ МЕТОДАМИ
}

Электро- и гравиразведка для определения мощности четвертичных отложений в Эстонии были впервые использованы в 1954 г. сотрудниками Института геологии АН ЭССР у пос. Пюсси в пределах древней погребенной долины Пуртсе. В начале 1960-х годов геофизические методы при проведении геологосъемочных и геологоразведочных работ стали широко применять геофизики Управления геологии СМ ЭССР.

В период 1971-1973 гг. Институтом геологии АН ЭССР были проведены исследования погребенных долин Северной Әстонии в целях установления распространения, строения и условий формирования долин и разработки комплексной геолого-геоморфологической методики их изучения. Основной задачей геофизических исследований было оконтуривание некоторых погребенных долин и, по возможности, определение мощности заполняющих их четвертичных отложений. При изучении погребенных долин гравиметрический метод применялся на всех профилях, а электропрофилирование и вертикальное электрическое зондирование (ВЭЗ) лишь на некоторых из них над долиной Пуртсе. Полевые работы и интерпретация материалов гравиразведки выполнены автором, а электроразведка - И. Юрине.

Определение $\Delta g$ на детальных профилях проведено с помощью гравиметра типа ГАК-7Т по схеме $1-2-3-4-5 \ldots 5-3-1$ короткими рейсами продолжительностью $1,0-1,5$. Смещение нуль-пункта используемого гравиметра составляло в среднем 0,23 мәл/ч. Отдельные профили были присоединены полигонами, невязка была уровнена. Полигоны были привязаны к опорным пунктам государственной сети трехкратным повторением.

Профили задавались по возможности поперек предполагаемого простирания погребенной долины, а расстояние между пунктами наблюдений выбиралось с учетом ее ширины. Для условий Северной Эстонии, где обычная ширина древних долин 0,6-2,5 $\mathrm{k \mu}$, шаг наблюдений был принят равным $50 \mathrm{~m}$. На профилях, где ширина долин составляла $0,2-0,6 \kappa м$, шаг наблюдений был принят равным 25 м. Анализ кривых $\Delta g$ показал, что при ширине долин $0,6 \kappa м$ и больше расстановка с шагом $50 \mathrm{M}$ вполне обеспечивает выявление характера поперечного разреза долины. При ширине долины $0,1-0,2 \kappa м$ расстояние между пунктами наблюдений должно быть $10-20$ м. Для получения высот пунктов наблюдения было проведено техническое нивелирование. 
Аномалию силы тяжести вычисляли по формуле:

$$
\Delta g=g_{0}+(0,3086-0,0419 \sigma) H-\gamma_{0},
$$

где $H$ - абсолютная высота точки наблюдения с гравиметром, $g_{0}-$ наблюденное значение силы тяжести, $\gamma_{0}$ - нормальное значение силы тяжести (по формуле Гельмерта 1901-1909 гг.), $\sigma$ - средняя плотность

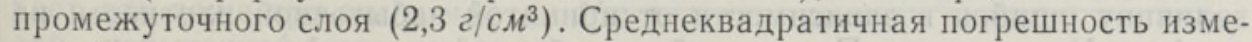
рений, определенная по формуле

$$
\Sigma= \pm \sqrt{\frac{\Sigma V^{2}}{m-n}}
$$

где $V$ - отклонение от среднего значения, $m-$ число наблюдений (192), $n$ - число контрольных точек (59), составляет $\pm 0,03$ мел.

Наблюдаемое аномальное поле отражает суммарное действие многих геологических факторов. Важнейшими из них являются мощность, состав и структурные особенности осадочных образований, рельеф поверхности и петрографическая неоднородность кристаллического основания, в частности наличие интрузивных тел кислого или основного состава, и глубинное строение земной коры. Это приводит к необходимости выделения непосредственно интересующих нас составляющих из всех возмущающих влияний. Обычно разделение гравитационных полей заключается в снятии регионального фона, имеющего общий характер для значительных областей и создаваемого глубоко залегающими крупными структурами, и выделении локальных аномалий, вызываемых местными неоднородностями. Снятие регионального фона можно провести графическим способом или численным методом, причем более удобен из них первый ввиду значительно меньшей трудоемкости. Для уверенного разделения полей необходимо постоянство региональной составляющей или ее одинаковое изменение на протяжении всего профиля. При измерениях в 1971-1973 гг. профили были достаточно длинными, что позволило применять для снятия регионального фона графический метод.

Используя формулу плоскопараллельной бесконечной пластины, можно определить мощность заполняющих долину осадков:

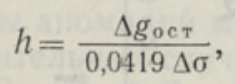

где $\Delta g_{\text {ост }}$ - величина остаточной аномалии силы тяжести, $\Delta \sigma-$ избыточ-

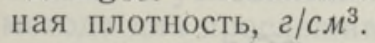

\begin{tabular}{|c|c|c|c|c|c|c|}
\hline \multirow{3}{*}{$\begin{array}{c}\text { Номер } \\
\text { скважины }\end{array}$} & \multirow{3}{*}{$\underset{2 / C M^{3}}{\Delta g}$} & \multicolumn{3}{|c|}{ Мощность четвертичных отложений, $м$} & \multirow{2}{*}{\multicolumn{2}{|c|}{ Ошибка, \% }} \\
\hline & & \multirow{2}{*}{$\begin{array}{c}\text { По дан- } \\
\text { ным бу- } \\
\text { рения }\end{array}$} & \multicolumn{2}{|c|}{$\begin{array}{c}\text { По данным грави- } \\
\text { разведки }\end{array}$} & & \\
\hline & & & $\Delta \sigma=0,36$ & $\Delta \sigma=0,30$ & $\Delta \sigma=0,36$ & $\Delta \sigma=0,30$ \\
\hline $\begin{array}{l}7863 \\
7861 \\
7857 \\
7858 \\
7862 \\
7859 \\
7860\end{array}$ & $\begin{array}{l}0,13 \\
0,15 \\
0,30 \\
0,51 \\
0,51 \\
0,25 \\
0,08\end{array}$ & $\begin{array}{r}9,0 \\
12,5 \\
31,4 \\
38,0 \\
42,2 \\
26,6 \\
8,0\end{array}$ & $\begin{array}{r}8,7 \\
10,0 \\
20,0 \\
34,1 \\
36,0 \\
16,7 \\
5,4\end{array}$ & $\begin{array}{r}10,4 \\
12,0 \\
24,2 \\
40,4 \\
43,1 \\
20,1 \\
6,4\end{array}$ & $\begin{array}{r}3,3 \\
20,0 \\
36,3 \\
10,1 \\
14,7 \\
36,9 \\
32,0\end{array}$ & $\begin{array}{r}15,5 \\
3,9 \\
23,8 \\
6,3 \\
2,1 \\
24,1 \\
20,0\end{array}$ \\
\hline
\end{tabular}

Таблица

Мощность четвертичных отложений на профиле Уникюла 
Избыточная плотность была подобрана путем сравнения остаточных аномалий с данными бурения. Соответственно геологическим условиям она составила $0,26-0,30$ г/ $\mathrm{cm}^{3}$. Правильный выбор избыточной плотности очень важен, так как при количественной интерпретации наибольшие систематические ошибки возникают именно в результате использования ее неверного значения. Таблица иллюстрирует сказанное. Она показывает величину ошибок в зависимости от принятой избыточной плотности на профиле Уникюла над Пуртсеской погребенной долиной.

Избыточная плотность $\Delta \sigma=0,36$ г/с ${ }^{3}$ определена по образцам, а $\Delta \sigma=0,30$ г/см ${ }^{3}$ вычислена по формуле (3), в которую значения мошности заполняющих долину осадков $(h)$ были введены по данным бурения. K сожалению, отсутствие данных бурения по многим профилям делает корректировку избыточной плотности невозможной, а малочисленность образцов четвертичных отложений и коренных пород не позволяет дать достаточно точную оценку ее величины.

В Северной Эстонии, где древние долины врезаны в карбонатные породы ордовика и силура, плотность четвертичных отложений, заполняющих древние долины, меньше плотности карбонатных пород, вследствие чего на кривой $\Delta g$ над долиной образуется минимум (рис. 1,2 ). Наиболее четкие остаточные отрицательные аномалии получены над долиной Вазавере $(0,86-1,28$ мгл) на восточной ее ветви. Над долинами Пуртсе и Кунда интенсивность аномалий меньше $(0,34-0,54$ и $0,33-$ 0,58 мел). В геологических условиях, где плотность четвертичных отложений близка к плотности коренных пород, аномалия силы тяжести выражена очень слабо или отсутствует совсем. Такие условия типичны, например, для предглинтовой части Эстонии, где древние долины врезаны в кембрийские песчаники и глины. Гравиметрический профиль над долиной Вяэна заложен недалеко от берега Финского залива. Были получены две аномалии интенсивностью 0,26 мәл над юго-западной и 0,20 мәл над северо-восточной ветвями долины. По данным буровой скважины,

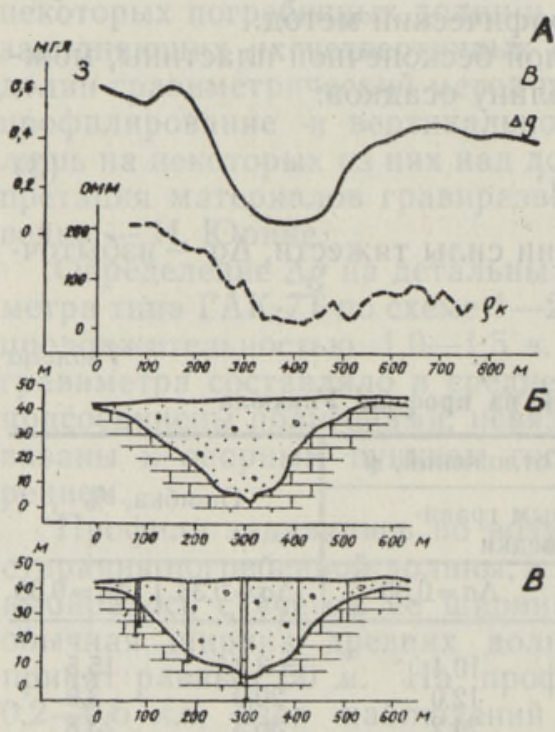

Рис. 1. $A-$ кривые $\Delta g$ и $\varrho_{h}$ над погребенной долиной Пуртсе у д. Уникюла. Геологические разрезы: $\quad$ по данным гравиразведки, $B-$ по данным бурения.
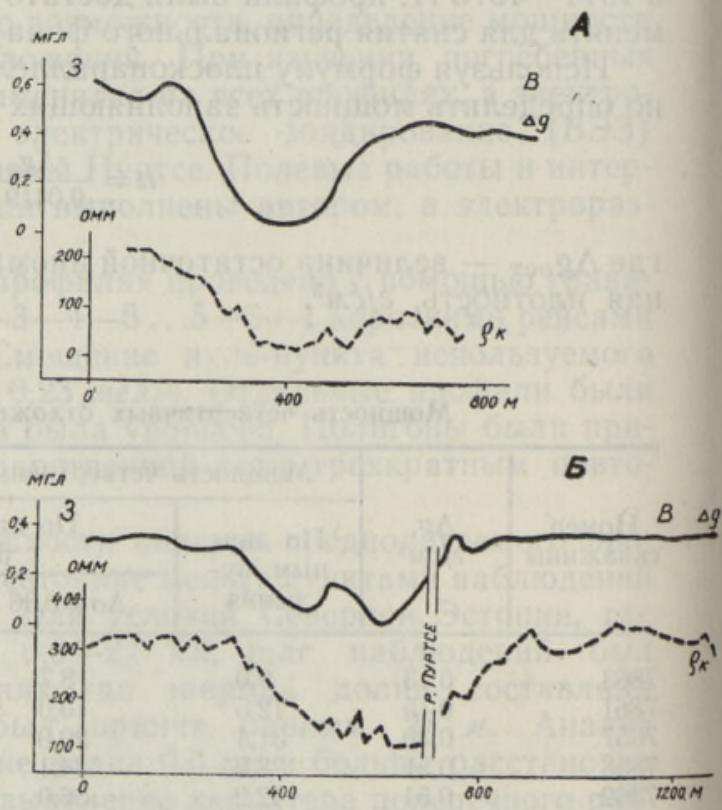

Рис. 2. Кривые $\Delta g$ и $\mathrm{g}_{k}$ над погребенной долиной Пуртсе у д. Уникюла $(A)$ и д. Хирмузе (Б). 
мощность четвертичных отложений в погребенной долине Вяэна составляет до $137 \mu$. Расчет по формуле (3) дает избыточную плотность 0,064

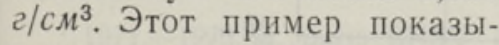
вает, что даже при очень малой избыточной плотности возможно выделение погребенной долины, если мощность четвертичных отложений достаточно большая.

В Южной Эстонии древние долины врезаны в девонские алевролиты, песчаники и глины, а наиболее глубокие из них - даже в силурийские карбонатные породы (Каяк и др., 1970). Плотность девонских отло-
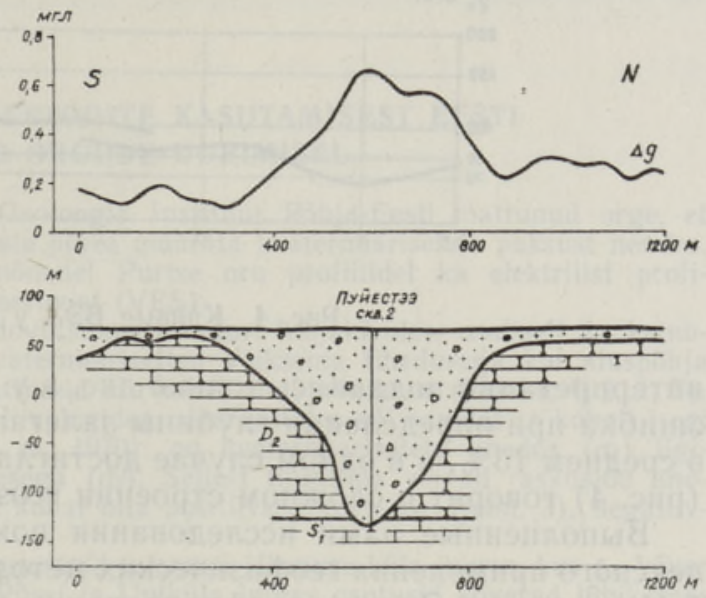

Рис. 3. Аномалия силы тяжести над погребенной долиной у д. Карукюла (Юго-Западная Эстония) и геологический разрез по данным гравиразведки. жений приблизительно равна плотности четвертичных отложений, заполняющих долины. По данным ГПИ «Эстпромпроект», плотность четвертичных отложений $\left(\sigma_{1}\right)$ может меняться от 1,56 (пески) до 2,16 г/см ${ }^{3}$ (морена), а плот-

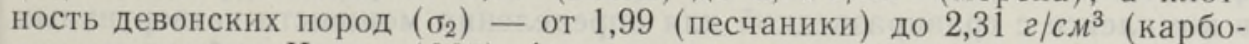
натные породы, Кулль, 1967). Аномалии $\Delta g$ над погребенными долинами в Южной Эстонии в соответствии с геологическими условиями могут быть отрицательными $\left(\sigma_{1}<\sigma_{2}\right)$, положительными $\left(\sigma_{1}>\sigma_{2}\right)$ или могут отсутствовать $\left(\sigma_{1}=\sigma_{2}\right)$. Близ д. Карукюла над древней долиной глубиной до $207 \mu$ наблюдается максимум силы тяжести интенсивностью 0,5 мел (рис. 3). Положительная аномалия объясняется несколько бо́льшей избыточной

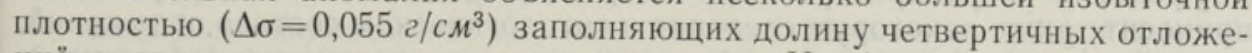
ний по сравнению с девонскими песчаниками. Необходимо учитывать, что слагающие долину отложения имеют очень сложное строение и поэтому форма кривой $\Delta g$ и амплитуды аномалий могут сильно изменяться вдоль долины, но и в таких затруднительных случаях обычно возможна уверенная корреляция аномалий. В Северной Латвии, где геологические условия сходны с условиями Южной Эстонии, применение гравиметрического метода для прослеживания погребенных долин дало хорошие результаты (Файтельсон, 1969).

Электропрофилирование в Северной Эстонии было выполнено симметричной установкой с $\mathrm{AB}=100 \mu, \mathrm{MN}=10 \mu$ и шагом наблюдений $25 \mu$. Наилучшие результаты были получены на профиле Хирмузе, где кривая электропрофилирования четко отбивает борта долины (рис. $2, \overline{6}$ ). Коренные породы характеризуются здесь сопротивлением $300-350$ омм, а заполняющие долину четвертичные отложения - около 150 омм. Ширина долины, по данным электропрофилирования, составляет около $500 \mu$. В пос. Пюсси и д. Уникюла электропрофили оказались слишком короткими, и по кривым $\sigma_{k}$ можно было определить только один борт долины (рис. $1, A$ и $2, A)$. При дальнейших исследованиях желательно использовать электропрофилирование на двух разносах. Последние следует выбирать таким образом, чтобы малый разнос обеспечивал изучение сопротивления и поведения первого слоя (Борков, Конишина, 1970).

ВЭЗ выполнялось симметричной установкой с максимальными разносами $\mathrm{AB} / 2=225$ м. У д. Уникюла из шести кривых ВЭЗ количестзенной 


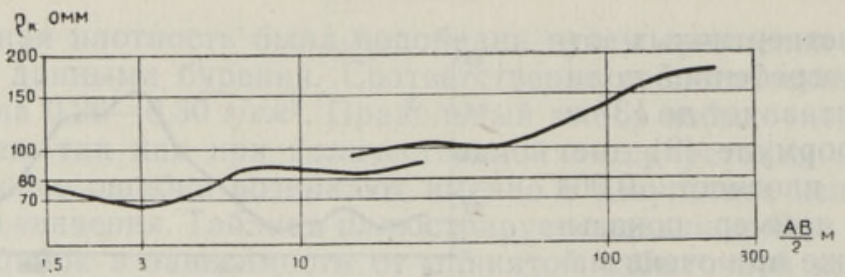

Рис. 4. Кривые ВЭЗ у д. Уникюла.

интерпретации поддались только две, а у д. Хирмузе из пяти три, причем ошибка при определении глубины залегания коренных пород составляла в среднем $13 \%$, а в одном случае достигла $32 \%$. Левая ветвь кривых ВЭЗ (рис. 4) говорит о сложном строении геоэлектрического разреза долины.

Выполненные нами исследования показали целесообразность комплексного применения геофизических методов при изучении древних погребенных долин. Электропрофилирование особенно эффективно для предварительного оконтуривания долин ввиду высокой разрешающей способности метода и большой экономии времени, затрачиваемого на полевые работы и интерпретацию результатов. Гравиразведку и ВЭЗ следует рекомендовать для уточнения ширины долины и определения мощности четвертичных отложений в долине. Когда по данным электропрофилирования ширина долины приблизительно известна, гравиразведочные профили можно заложить точнее и с наименьшими затратами времени. ВЭЗ в комплексе с гравиразведкой для определения мощности четвертичных отложений в погребенных долинах следует использовать особенно в местах, где бурение контрольных скважин не предусмотрено. При совпадении результатов гравиметрии и ВЭЗ данные можно считать достаточно достоверными.

Геофизические методы дают возможность получать информацию о морфологии и распространении погребенных долин. Электроразведка приносит также некоторые сведения о литологическом составе отложений, но только при наличии большой разницы в электрическом сопротивлении какого-либо горизонта и выше- и нижележащих отложений (сухие пески, глины). Самые достоверные данные об отложениях дает, безусловно, бурение. Результаты геофизических исследований позволяют точнее и рациональнее размещать буровые скважины по профилям.

Первоочередной задачей на данном этапе исследований остается более точное определение мощности четвертичных отложений в погребенных долинах. Поскольку при интерпретации гравиметрических данных наибольшая ошибка возникает из-за неправильного определения избыточной плотности, необходимо более подробно изучать физические свойства пород и в первую очередь их плотность и удельное электрнческое сопротивление.

\section{Л И Т Е РА Т У Р А}

Борков В. С., Конишина Ю. П. 1970. Поиски и разведка месторождений строительных материалов геофизнческими методами. М.

Қ а я к К., Пу н н и н Г Я.-М., Р а у к а с А. 1970. Новые данные о геологии разреза Карукюла (Юго-Западная Эстония). Изв. АН ЭССР, Хим. Геол., 19, № 4.

К улль И. И. 1967. Северо-Западная часть Русской платформы (Эстонская ССР). В сб.: Физические свойства осадочного покрова территории СССР. М.

$\Phi$ а й тель с он А. М. 1969. Прослеживание четвертичных долин гравиметрическим методом. Разведочная геофизика, 35, № 1. 


\section{GEOFUUSIKALISTE MEETODITE KASUTAMISEST EESTI MATTUNUD ORGUDE UURIMISEL}

1971.-1973. a. uuris ENSV TA Geoloogia Instituut Põhja-Eesti mattunud orge, et selgitada nende paiknemist ja võinaluste piires määrata kvaternaarisetete paksust nendes. Rakendati gravimeetrilist meetodit, mōnedel Purtse oru profiilidel ka elektrilist profileerimist ja vertikaalset elektrilist sondeerımist (VES).

Põhja-Eestis, kus orud asuvad ordoviitsiumi ja siluri lubjakivides, osaliselt ka kambriumi liivakivides, on orgu täitvad kvaternaarisetted väiksema tihedusega kui aluspō̉ıja kivimid, mistōttu $\Delta g$ kõveral esineb mattunud oru kohal alati miinimum (joon. $1, A ; 2, A, \overline{\text { ) }}$. Lõuna-Eestis, kus orud asuvad devoni liivakivides, aleuroliitides vōi savides ja kohati isegi siluri karbonaatsetes kivimites (Каяк jt., 1970), on kvaternaarisetete tihedus $\left(\sigma_{1}\right)$ ligikaudu võrdne aluspõhjakivimite tihedusega $\left(\sigma_{2}\right)$. Sellest tingituna võivad raskusjõu anomaaliad Lõuna-Eesti mattunud orgude kohal olla positiivsed $\left(\sigma_{1}>\sigma_{2}\right)$ (joon. 3), negatiivsed $\left(\sigma_{1}<\sigma_{2}\right)$ vōi puududa $\left(\sigma_{1}=\sigma_{2}\right)$.

Elektrilise profileerimisega saadi paremaid tulemusi Hirmuse küla juures, kus $\varrho_{4}$ kõver joonistab välja oru nõlvad (joon. 2). Püssi ja Uniküla juures osutusid kõverad lühikeseks ja nende järgi oli võimalik määrata ainult oru ühe nõlva asukoht (joon. $1, A ; 2, A$ ).

VES-i kōveratest olı vöimalik interpreteerida kuuest Uniküla juures tehtust kahte ja viiest Hirmuse küla juures tehtust kolme. Kõverate vasakpoolse osa keerulisus (joon. 4) näitab orgude geoelektrilise läbilōike keerukust.

Olemasolevate andmete alusel võib pidada Põhja-Eesti mattunud orgude uurimisel sobivamateks geofüüsikalisteks meetoditeks elektrilist profileerimist (oru paiknemise ligikaudseks määramiseks) ning gravimeetrilist meetodit ja VES-i (kvaternaari sete paksuse määramiseks). Viimaseid on soovitatav kasutada koos, eriti kui ei ole ette näha kontrollpuurimisi.

\section{Elvi JURIMA}

\section{GEOPHYSICAL INVESTIGATIONS OF BURIED VALLEYS IN ESTONIA}

Geophysical measurements were made in North Estonia in 1971-1973 by the Institute of Geology for determining the thickness of sediments in the buried valleys and their area of distribution. The gravimetrical method was used in all profiles and electrical methods in several profiles only across the buried valley of the River Purtse.

The residual gravity anomaiies are always negative in North Estonia (Figs 1, A; 2, A, E) because the density of Quaternary deposits in the valleys $\left(\sigma_{1}\right)$ is smaller than the density of the sedimentary rocks $\left(\sigma_{2}\right)$. The curve obtained and the available drilling data correlate well (Fig. 1 and Table). In South Estonia, where the density of the Quaternary deposits and the density of the bedrock is approximately equal, the residual anomalies may be positive $\left(\sigma_{1}>\sigma_{2}\right)$ (Fig. 3), negative $\left(\sigma_{1}<\sigma_{2}\right)$ or altogether lacking $\left(\sigma_{1}=\sigma_{2}\right)$.

The resistivity curve of horizontal profiling indicates the position of the buried valley best near the village of Hirmuse (Fig. 2, 5 ). The resistivity profiles near the villages of Püssi and Uniküla were rather short, and it was impossible to locate two slopes of the valley (Figs $1, A ; 2, A$ ). Resistivity soundings for determining the Quaternary deposits in the valleys were carried out near the villages of Uniküla and Hirmuse. 50 per cent of the sounding curves observed do not fit the master curves. The left part of the sounding curve (Fig. 4) refers to the complication of the geoelectrical section in the buried valleys.

The study showed that the gravimetrical method in conjunction with resistivity prospecting is very useful for determining the thickness of the Quaternary deposits and their distribution in buried valleys. 